\title{
PENINGKATAN KETERAMPILAN GURU SEKOLAH DASAR DALAM PENAYANGAN VIDEO PADA MICROSOFT POWERPOINT DENGAN TEKNIK HYPERLINK
}

\author{
${ }^{1}$ Usman Sutisna, ${ }^{2}$ Mia Fitriah Elkarimah \\ ${ }^{1,2}$ Universitas Indraprasta \\ Email: al.karimah@gmail.com
}

\begin{abstract}
In the DKI Jakarta area, in the 2019/2020 school year it is almost certain that all schools in the Ministry of Education and Culture and the DKI Jakarta Education Office have compiled the 2013 curriculum. How to understand this 2013 curriculum encourages teachers to improve their quality and professionalism as educators adjusted to the needs of the present. The thing that is highlighted the most is the ability of a teacher in information technology literacy that is good at accessing and using the technology itself. At the same time in Menteng Atas Elementary School 02 Morning, there are still not a few teachers who have not mastered specific information technology in order to make IT-based learning media, therefore related to the team from Unindra will help community service to help teachers in doing communication 2013 (kurtilas) one of them with the help of teachers in providing learning using video media in PowerPoint with hyperlink techniques. Hopefully with community service activities we can help in developing and improving the professionalism of teachers in the field of information technology.
\end{abstract}

Keywords: Teacher Skills Improvement, Microsoft Powerpoint, Hyperlink

\begin{abstract}
ABSTRAK
Di wilayah DKI jakarta, pada tahun ajaran 2019/2020 maka hampir dipastikan bahwa seluruh sekolah di bawah naungan Kemendikbud dan Dinas Pendidikan DK Jakarta sudah melaksanakan kurikulum 2013. Seperti diketahui bahwa kurikulum 2013 ini mendorong para guru untuk meningkatkan kualitas dan profesionalitasnya sebagai seorang tenaga pendidik yang disesuaikan kebutuhan pada masa sekarang. Hal yang paling disoroti adalah kemampuan seorang guru dalam literasi teknologi informasi baik dalam mengakses maupun menggunakan teknologi itu sendiri. Pada saat yang sama di sekolah SDN Menteng Atas 02 Pagi, ternyata masih terdapat beberapa guru yang belum menguasai teknologi informasi khusus dalam rangka membuat media pembelajaran berbasis IT, oleh karena itulah tim dari Unindra akan melaksanakan pengabdian kepada masyarakat untuk membantu mempermudah guru dalam menghadapi kurikulum 2013 (kurtilas) salah satunya dengan membantu guru dalam memberikan pembelajaran menggunakan media video dalam powerpoint dengan teknik hiperlink. Semoga dengan kegiatan pengabdian masyarakat yang kami lakukan dapat membantu dalam mengembangkan dan meningkatkan profesionalisme para guru di bidang teknolog informasi.
\end{abstract}

Kata Kunci: Peningkatan Keterampilan Guru, Microsoft Powerpoint, Hyperlink 


\section{Rangkiang: لlurna/ Pengabdian Pada Masyarakat \\ UPSM STKIP PGR/ Sumatera Barat}

ISSN: (2721-2688) Vol. 2 No. 1 (Juni 2020): 28-31

https://doi.org/10.22202/JR.2020.V1i2.3929

\section{PENDAHULUAN}

Banyak guru yang masih bingung dan meraba dalam kurikulum ini sehingga diperlukan media pembelajaran agar mudah dipahami. Perubahan kurikulum 2013 berdampak pada pendekatan metode pembelajaran, guru dituntut harus melek literasi, guru dituntut untuk menguasai IT dan pada waktu yang sama di SDN Menteng Atas 02 Pagi masih banyak guru yang kurang menguasi IT terutama dalam membuat bahan materi ajar berbasis computer. Oleh karena itu team Abdimas merasa perlu memberikan pelatihan khusus kepada dewan guru di SDN Menteng Atas 02 Pagi, sebagai cara untuk mempermudah guru dalam menghadapi kurikulum 2013 (kurtilas) salah satunya dengan membantu guru dalam memberikan pembelajaran menggunakan media video dalam powerpoint dengan teknik hiperlink.

Istimewanya Kurikulum 2013 terutama untuk Kurikulum Sekolah Dasar adalah Pembelajaran tematik-integratif. Kurikulum 2013 menerapkan pembelajaran tematikintegratif untuk seluruh jenjang kelas, ini berbeda dengan penerapan pembelajaran pada kurikulum sebelumnya, yang hanya menerapkan pembelajaran tematik (hanya tematik, tanpa tambahan integratif) pada siswa kelas I - III. Sedangkan untuk kelas IV - VI, pembelajarannya berbasis mata pelajaran. Pendekatan saintifik. Berbeda dengan pendekatan pembelajaran pada kurikulum sebelumnya, pada kurikulum 2013, pendekatan pembelajaran yang digunakan adalah pendekatan saintifik. Pendekatan saintifik (ilmiah) dalam pembelajaran dimaksudkan bahwa pembelajaran harus didasarkan pada fakta, bukan sekadar kira-kira. Dalam praktiknya, pembelajaran ini meliputi kegiatan mengamati, menanya, mengumpulkan informasi, menalar, menarik kesimpulan, mengomunikasikan. Penilaian autentik. Penilaian yang digunakan dalam kurikulum 2013 adalah penilaian autentik. Yakni penilaian yang menampilkan tugas atau situasi yang sesungguhnya yang mendemonstrasikan penerapan keterampilan dan pengetahuan esensial yang bermakna; menggunakan berbagai cara dan kriteria holistik (kompetensi utuh merefleksikan pengetahuan, keterampilan, dan sikap). Penilaian ini mencakup penilaian proses, penilaian produk, dan penilaian sikap.

Kurikulum 2013 (Kurtilas) adalah kurikulum yang berlaku dalam Sistem Pendidikan Indonesia. Kurikulum ini merupakan kurikulum tetap diterapkan oleh pemerintah untuk menggantikan Kurikulum-2006 (yang sering disebut sebagai Kurikulum Tingkat Satuan Pendidikan) yang telah berlaku selama kurang lebih 6 tahun. Semua Sekolah Dasar wajib menggunakan Kurikulum 2013 (Kurt Menurut Undang-undang Nomor 20 Tahun 2003 tentang Sistem Pendidikan Nasional Pasal 1 butir 19, kurikulum adalah seperangkat rencana dan pengaturan mengenai tujuan, isi, dan bahan pelajaran serta cara yang digunakan sebagai pedoman penyelenggaraan kegiatan pembelajaran untuk mencapai tujuan pendidikan tertentu. Kurikulum biasanya dibedakan antara kurikulum sebagai rencana dengan kurikulum yang fungsional. Rencana tertulis merupakan dokumen kurikulum, sedangkan kurikulum yang dioperasikan di dalam kelas merupakan kurikulum fungsional (Nana Syaodih, 2009: 5).

Pelaksanaan kurikulum 2013 sudah dilaksanakan hampir sudah menyeluruh di satuan pendidikan dan diharapkan pada tahun 2019 seluruh sekolah sudah dapat menggunakan kurikulum 2013 ini secara nasional. Guru dan kepala sekolah di berbagai sekolah sudah dibekali melalui pendidikan dan pelatihan (diklat) implementasi kurikulum 2013, walaupun pelaksanaannya belum semuanya menggunakan akan tetapi bertahap. Ditahun ajaran baru ini 2019/2020 semua sekolah wajib menggunakan kurikulum 2013 (Kurtilas). Para guru kelas yang akan melaksanakan kurikulum tersebut sudah mengikuti pelatihan. 


\section{METODE}

Metode yang digunakan dalam pelaksanaan ini adalah pelatihan dengan cara membuat langkah langkah dalam menampilkan media video dalam power point secara sederhana, kemudian dengan Implementasi Setelah selesai melakukan pelatihan bisa dilanjutkan membuat modul tutorial Microsoft power point berbasis media video teknik hyperlink.

Tahap-tahap dalam pelaksanaan kegiatan pengabdian masyarakat dibagi menjadi beberapa tahap diantaranya sebagai berikut: Tahap awal Persiapan, pelaksanan dan evaluasi. Sedangkan waktu kegiatan pengabdian masyarakat adalah bulan September s.d Desember 2019

\section{HASIL DAN PEMBAHASAN Realisasi Pelaksanaan Kegiatan}

Pada awal kegiatan Kepala Sekolah dan Wakil Kepala SDN Menteng Atas 02 Pagi memberikan sambutan sekaligus membuka kegiatan pengabdian masyarakat yang berjudul "PKM Peningkatan Keterampilan Guru Sekolah Dasar Dalam Penayangan Video Pada Microsoft Powerpoint Dengan Teknik Hyperlink". Pada sambutannya, Kepala Sekolah menghimbau agar para guru diharapakan dapat mengikuti kegiatan abdimas yang diadakan oleh tim, sehingga apa yang menjadi tujuan kegiatan dapat terlaksana dengan baik. Karena ada kepentingan dinas ibu Kepala Sekolah langsung meninggalkan ruangan kegiatan dan dilanjutkan oleh ibu Wakil Kepala Sekolah yang pada intinya menerima kegiatan pengabdian masyarakat dengan baik dan meminta agar seluruh peserta yang hadir dapat mengikuti pelatihan dengan seksama.

Tim abdimas mengucapkan terima kasih kepada Kepala Sekolah dan Wakil Kepala SDN Menteng Atas 02 Pagi yang telah memberikan izin untuk melaksanakan kegiatan abdimas ini, serta kepada para guru yang sudah meluangkan waktunya untuk mengikuti kegiatan pelatihan yang telah direncanakan oleh tim. Dengan diadakannnya kegiatan ini, diharapkan Unindra dapat dikenal lebih luas oleh masyarakat khususnya warga sekolah SDN Menteng Atas 02 Pagi, selanjutnya juga tim berharap agar kegiatan ini dapat membantu para guru dalam meningkatkan kemampuan profesional khususnya dalam bidang IT dan tujuan akhir dari kegiatan abdimas ini diharapkan dapat mendorong para guru untuk sama-sama bisa memanfaatkan media pembelajaran khususnya media powerpoint dalam rangka menunjang keberhasilan tujuan pembelajaran dalam kurikulum 2013.

Setelah acara sambutan selesai, kegiatan selanjutnya adalah tahap pelaksanaan. Tahap pelaksanaan dibagi menjadi dua tahap yakni tahap pelatihan dan tahap pendampingan. Pada saat kegiatan pelatihan, tim abdimas menyampaikan materi tentang pembuatan powerpoint yang baik sekaligus memberikan teknik menampilkan video mulai dari cara mendownload lalu menampilkan dalam powerpoint dengan teknik hyperlink. Selanjutnya didiadakan sesi tanya jawab dari peserta dan narasumber tentang materi yang telah disampaikan.

Setelah dikusi selesai, waktunya tim melakukan pendampingan bagi para peserta dalam rangka memberikan bantuan tentang cara membuat powerpoint yang epektif dan efisien. Dari hasil pengamatan tim rata-rata peserta mampu menggunakan teknologi berbasis internet sehingga dalam mengakses bahan pembelajaran yang diperlukan tidak mengalami kesulitan yang berarti.

Tujuan dari kegiatan pengabdian masyarakat ini, yaitu memberikan pelatihan kepada guru-guru bagaimana membuat microsoft powerpoint dalam menunjang tujuan pembelajaran 
pada kurikulum 2013. Untuk mewujudkan tersebut, tim hanya memberikan pelatihan saja tentang cara mendownload video dari You Tube lalu menyimpannya di perangkat lalu menampilkan dalam microsoft powerpoint yang efektif dan efisien dalam pembelajaran kurikulum 2013. Setelah para guru sudah dapat membuat video pembelajaran secara mandiri, maka diharapkan dapat membantu melaksanakan kegiatan pembelajaran yang lebih epektif dan menyenangkan.

Berdasarkan fakta di lapangan, terdapat beberapa guru yang masih kesulitan untuk menggunakan perangkat computer melalui laptop, tetapi karena banyak teman-teman guru di sana yang sudah mahir komputer serta pendampingan dari tim, maka hampir dipastikan seluruh guru akhirnya dapat membuat powerpoint secara mandiri. Secara keseluruhan pelatihan yang dilaksanakan oleh tim dapat berjalan dengan lancar, para peserta sangat antusias mengikuti pelatihan, hal itu dapat dilihat dari beberapa pertanyaan yang diajukan dari para peserta terkait materi apabila masih ada hal-hal yang belum jelas atau belum dipahami.

\section{KESIMPULAN}

Hasil dari kegiatan pengabdian masyarakat adalah para guru SDN Menteng Atas 02 Pagi Setiabudi Jakarta Selatan mampu memperoleh pengetahuan tentang pembuatan microsoft powerpoint dan menampilkan video pembelajaran secara mandiri. Sehingga para guru diharapkan dapat menggunakan media pembelajaran dalam meningkatkan kualitas guru dan suasana kegiatan pembelajaran guna mendukung program kurikulum 2013 yang dicanangkan oleh pemerintah.

\section{DAFTAR PUSTAKA}

Mulyasa, Konsep Kurikulum 2013 (Jakarta : Buana Cipta, 2016)

Rachmad, Antonius. 2005. "Pengantar Multimedia". Yogyakarta: Fakultas Teknik Informatika Universitas Kristen Duta Wacana.

Suheri, Agus. 2006. Animasi Multimedia Pembelajaran, Jurnal Media Teknologi, Vol. 2, No. 1. Cianjur: Universitas Suryakencana.

Utami, Dini. 2007. Animasi Dalam Pembelajaran. Yogyakarta: UNY.

Wahyu S, Novian. 2005. "Pengembangan Media Pembelajaran Berbasis Multimedia". Semarang: UNNES.

Zainal Arifin. "Konsep dan Model Pengembangan Kurikulum”. (Bandung: Remaja Rosdakarya, 2009). 